\title{
Mine Seismology for Rock Engineers- An Outline of Required Competencies
}

\author{
F. Essrich SiM Mining Consultants (Pty) Ltd, South Africa
}

A decline in the number of dedicated mine seismologists on SA mines over the past decade has created a need for Rock Engineers to acquire a level of competency in mine seismology that would allow them to fulfil a number of functions previously occupied by mine seismologists. The parallel development of user friendly software as a tool for basic seismic data analysis has added to these requirements by offering the non-specialist user an opportunity to carry out various forms of seismic data analysis. A further influence arises from the fact that seismology services are now outsourced on many mines, leaving rock engineering departments with the responsibility to control seismology contracts and liaise with suppliers, which adds managerial functions to their role in an already technically demanding field.

This paper investigates the new role embraced by rock engineers on seismically active mines and suggests an outline of training contents that is able to provide the knowledge and skills required. The author has presented training courses with contents similar to those outlined here to rock engineering consultancies and mining houses in South Africa.

\section{INTRODUCTION}

\subsection{Mine Seismologists in South Africa}

The development of digital seismic systems in the early 1990s and their installation on rockburst prone mines led to a proliferation of seismic data and the employment of specialised personnel in the field of mine seismology. Around 1996 the gold mining sector in South Africa had 24 mine seismologists to manage seismic systems, analyse and evaluate data and supply relevant information to mainly rock engineers, production personnel and mine management. Mine seismologist can be broadly defined as follows:

Any person, irrespective of background and formal training, whose sole responsibility is the management of seismic systems and / or the analysis and evaluation of seismic data originating from mining operations.

Mine seismologists were, with the exception of two corporate seismologists, employed by the mine and integrated into the mine's rock mechanics departments. This setup - considering seismology part of rock engineering - has developed from the perception that seismic information is best utilised in the department responsible for mine layout and support design. It ignores the fact that, academically, seismology forms part of geophysics, which is in some countries considered part of the geology discipline (USA) and in others part of the science of physics (Germany and France).

Instead of being integrated with rock engineering, mine seismologists could have joined the prospecting divisions of mining houses and then be seconded to mines as the need arises. This would have opened up more career prospects and may have retained some of the seismologists in the field, preventing the exodus that took place in the second half of the 1990s.

By mid 2001, AngloGold Ltd. (now AngloGold-Ashanti) had lost all of its mine seismologists bar one on corporate level. Out of the original 24, eight changed their working field and four left the country. Gold Fields Ltd. retained three of its six experts, plus one on corporate level. Of those leaving the mines, six individuals joined existing or opened up their own consultancies, all of which are still in business today, three years later.
By mid 2004, the number of mine-based and employed seismologists stood at four, only one of which is on a mine not previously served in this way. The number of individuals in consultancies has recently increased to ten due to demand by Harmony GM Co. Ltd. Generally speaking, consultancies have taken over the role of service providers in the field, operating seismic networks, managing the gathered data and analysing and evaluating data for most rockburst prone mines.

In this environment mine employed rock engineers become primary customers of seismology services. They are in charge of controlling the contracts with service providers, but also carrying out basic analysis of seismic data with specialised software tools that are licensed to rock engineering departments.

A closer look at the various functions executed during seismic data interpretation reveals requirements for senior rock engineering personnel whose responsibilities include seismology related tasks.

There are four discernible task groups that rock engineers have to cover in such an environment:

Input into mine planning: Design bracket pillars for seismically active structures; optimal face layout and mining sequence, production rate and face configuration to minimise seismic energy emission; optimal placement of stability pillar and their dimensions;

Support systems design: Evaluate rockburst information and peak ground motion estimates to recommend excavation support patterns for dynamic loading conditions;

Hazard identification: Correlate trends and patterns in seismicity with information from other disciplines (geology, production, rock mechanics) for detection of potentially hazardous developments;

Contract management: Liaison with suppliers; reviews and audits; quality control and other functions required to administer contracts with seismic service suppliers.

The first three points require a basic appreciation of mine seismology issues and an ability to apply such knowledge. Where it can contribute to safer mining environments 
seismology provides meaningful answers to relevant questions. Rock engineers need to be able to ask the right questions and fully comprehend the answers.

The last point assumes sufficient knowledge of seismic data quality and basic analysis methods to conduct audits and evaluate various aspects of supplier service delivery.

The following outlines not only essential considerations, but also explains some of the tools that are currently available for lay users.

\subsection{Mine Seismology: User-Friendly Tools}

Some of the first MS-WINDOWS based software codes for seismic data analysis on South African mines were developed between 1993 and 1998: A group of AngloGold (then Anglo American) specialists serving mines in its Vaal River Operations developed SEISDBS, which was intended for data base administration and data analysis of previously collected raw data. SEISDBS used data exported from ISS International seismic systems (van der Merwe, 1998). The other WIN-based package originated from CSIR-Miningtek for operation of their commercial PRISM system, a digital seismic system for mines developed together with M\&M Systems and in competition to ISS International, whose main platform at that time was Unix/Linux.

In 1998, the Council for Geoscience in Pretoria released SeisHazM [Kijko et al., 1998], a specialised tool for static seismic hazard assessment. This software was the main deliverable of SIMRAC ${ }^{1}$ project GAP517 and ran under WIN. It allowed users to calculate estimates of maximum expected magnitude and probability of occurrence of seismic events in different magnitude ranges, based on historic data sets recorded in an area.

Since 2000, HAMERKOP Scientific Services offers a suite of programs that can perform specialised types of analyses (Gutenberg-Richter analysis, Energy-Moment analysis, various statistical functions) as well as network performance modelling for a given network layout (sensitivity, location accuracy). All of these run on standard office PCs with system requirements lower than those needed for elastic rockmass modelling packages.

Following the general trend, ISS International also created WIN based versions of its software for system operation, data processing and data analysis. Tools currently available are considered user-friendly as they only require moderate amounts of training and can be operated on standard office computer hardware. Programs allow even non-seismologists to obtain useful analysis results that can be combined with other geotechnical information to contribute to rock engineering solutions.

The opportunity for rock engineering personnel to carry out seismological analysis on an elementary level and the availability of suitable tools partly determines the skill profile of rock engineers. It adds to their required knowledge base and should be accommodated with corresponding training needs.

\subsection{The Process: Seismic Data Interpretation}

Seismic data interpretation, as a process, transforms specific inputs into specific outputs. Formally, interpretation of data is the separator situated between the two as shown in Figure 1. Any person involved with the task of interpretation needs to be familiar with the specifics of the elements entering and leaving the core function of interpretation.

The tools and methods of data analysis, the raw data that has been collected with seismic monitoring systems, and the skills and knowledge of those performing the

Safety in Mines Research Advisory Committee, S. Africa interpretation are most relevant on the input side. On the output side, emphasis rests on the information type supplied to customers and the application of knowledge gained from data. Procedures need to ensure good communication, compliance with requirements and adequate response to the information received. Customers need to be competent in the use of seismic information.

There are comprehensive text books that deal with the hard- and software components of mine based seismic systems, most notably Mendecki (editor, 1997). Gibowicz \& Kijko (1994) discuss theoretical concepts of seismic failure mechanisms, source quantification and elastic wave propagation, on a level that exceeds the requirements for non-seismologists.

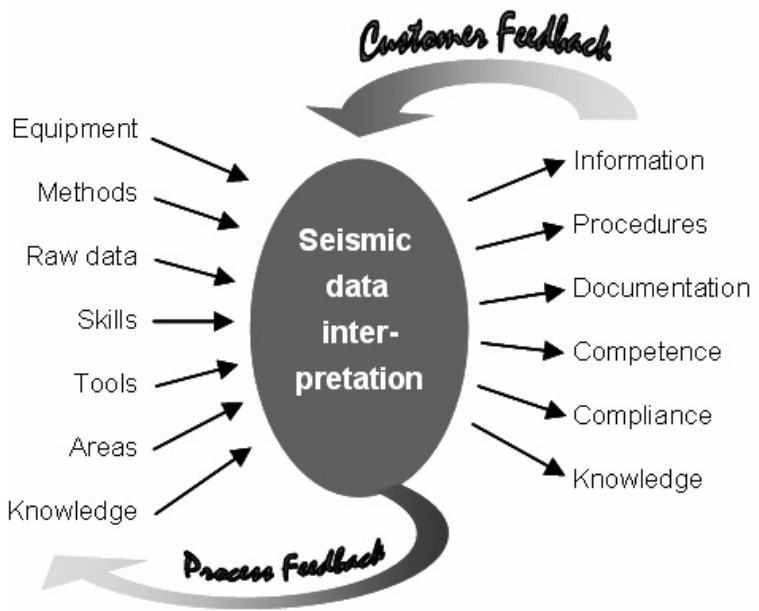

FIG. 1 Seismic data interpretation process (adapted from Oakland, 2003): Inputs (left) and outputs (right); relevant feedback functions

More important for rock engineers than detailed technical knowledge is the understanding of seismic data evaluation as a process, i.e. the transformation of raw data with the help of tools and methods into useful seismic information that can be applied to solve rock related problems. The co-operation of recipients of seismic information with network suppliers and those conducting data analysis and evaluation is essential for a successful management of seismic risks. Customer feedback to seismologists in charge of the core process and the core's feedback to the input side ensure continued exchange and improvement of the overall process (Figure 1).

Rock engineering practitioners and production personnel need to formulate their requirements in terms of information type and communication intervals; and the process core needs to be able to determine inputs (tools, methods, data, skills etc.) to enable provision of the required information. Feedback can be continuous or through a periodic, scheduled review process. Customers occupy the most important role and should be the ones to drive the review process.

\section{MAIN FUNCTIONS AND RESPONSIBILITIES}

A simplified model is introduced to describe main functions in the field of mine seismology. Then we focus on specific rock engineering issues that can be addressed with the aide of seismic data interpretation. We conclude with a description of administrative duties related to contract management and quality control.

\section{OSCAR}

The acronym OSCAR stands for Objectives - Systems Collection - Analysis - Reduction; or, in an expanded form: Monitoring objectives, seismic systems design and 
installation, data collection, data analysis, risk reduction. These are keywords representing five major elements in a loop of continuous improvement aimed at reducing the most pressing seismicity related risks (Figure 2).

Risk reduction, the last element, is linked to the first by evaluating the success of risk treatment campaigns and subsequently adjusting monitoring objectives. For instance, once a seismically active remnant has been successfully extracted, there is no longer a need for detailed coverage of this area. Resources can rather be spent on monitoring other sources of seismic energy emission.

Rock engineers who wish to familiarise themselves with the full scope of mine seismology, albeit with limited detail, could use the OSCAR model as a memory aid. It explains the main steps and the functionality of major elements of applied mine seismology.

\subsubsection{Monitoring objectives}

Monitoring objectives need to be formulated - and regularly reviewed - to define the desired outcomes of seismic monitoring on a mine. Three areas need to be visited to derive such objectives:

Need What aspect of seismicity needs to be quantified, i.e. which source parameters and at what level of accuracy?

Location Where are the areas that experience seismicity, i.e. what is the geographical distribution of seismicity and rockbursts?

Method How are objectives to be met, i.e. which resources are available and what is the time frame for implementing the monitoring program?

In order to answer the first question, knowledge of the following is required:

- Seismic source types

- Source parameters

- Methods of analysis

The second question could be approached by conducting an analysis of geographical distribution of seismicity incidents for which no specialised skills are required.

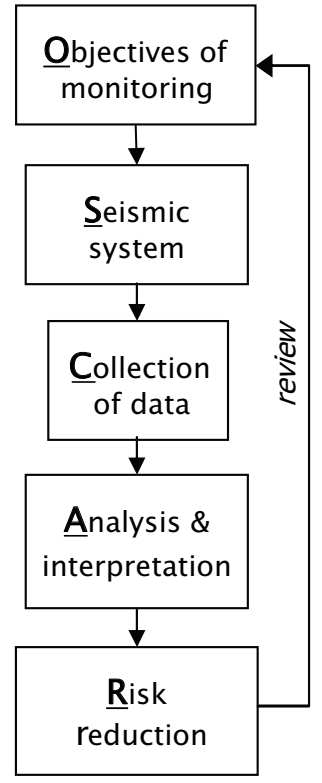

FIG. 2 The OSCAR cycle: The major elements of applied mine seismology

The answer to question three is usually dictated by the needs of the larger mining operation: Degree of urgency, legal requirements and budgetary constraints may play a role. The formulation of objectives under consideration of financial and other constraints is then followed by seismic system design and installation.

\subsubsection{Seismic system}

A seismic system consists of a combination of network hardware and software that allows the collection of seismic data, data processing for basic event parameters, and the creation of data bases from this data. The design of a suitable system is therefore directly linked to the aims of monitoring: Requirements such as spatial coverage, spatial/temporal resolution, choice of suitable sensors, and the quantification of various aspects of seismicity must enable the generation of seismic information to meet these objectives.

Selection of the system will naturally involve system suppliers, but an understanding of the following topics ensures an independent and informed decision by the advising rock engineer:

- Physics of oscillation

- Wave types

- Wave propagation

- Interfaces

- Network types

- Sensor types

- Methods of data transfer

- Network performance criteria

- Product costs

- Limitations of methods

Particular the last item, which refers to limitations of methods to record ground motion, invert for seismic source parameters (location in time and space, seismic energy release, seismic moment, local magnitude etc.) and subsequently assign a physical interpretation to these parameters, needs to be understood by everyone involved in system selection.

Calculation of source parameters and event locations is generally based on idealised conditions that are never truly met in nature (homogenous, elastic and isotropic medium). The consequence for system design is that each system configuration, in combination with system settings, results in a specific capability to record, process and store data. Design and configuration must therefore be adapted to local requirements as formulated in the monitoring objectives.

\subsubsection{Data collection}

Successful system installation is followed by data gathering, which comprises recording, automatic and manual processing to derive source quantification, and storage. This is a specialised field that requires input from technicians, IT system administrators and system operators under guidance of a mine seismologist.

A rock engineer typically requires little knowledge of the operation of such networks other than that of key indicators which would enable her to perform a review function:

- System down time

- Station down time

- Ratio accepted/rejected events

- Average repair time of units

- Location accuracy

- Sensitivity

These variables allow an effective comparison of the actual system performance with pre-set targets that need to be monitored over time. Knowledge of methods to determine location accuracy and network sensitivity is required.

At times, rock engineers may be facilitating the communication and interaction between the seismic network operator and the mine's engineering function. For instance, on 
local mines only mine employed electricians are authorised to work on the electrical infrastructure to ensure uninterrupted power supply to seismic stations.

\subsubsection{Data analysis}

The methods of seismic data analysis consist of specialised tools used in seismology, and many others that are regularly used in applied science. Rock engineers who receive the results of seismic data analysis need to be familiar with both.

Among the specialised tools are those that are capable of characterising single seismic failures and are used in global earthquake seismology:

- Location in space and time

- Slip-Burst type distinction

- Stress-drop estimate

- Source dimension estimate

- Peak Particle Velocity estimates

- Peak Particle Acceleration estimates

- Moment Tensor inversion

- Seismic hazard quantification

- Seismic risk quantification

In addition, the field of mine seismology has added its own set of tools through research and empirical investigations. Some of these are mere manipulation tools adapted from the descriptive statistics discipline, and most apply to groups of events rather than single events:

- Gutenberg-Richter graph

- Event probability

- Event predictions

- Success rate

- Energy Index

- Maximum size estimates

- Energy-Moment relation

- Time-History analysis

Any recipient of analysis results should be familiar with the methods applied, the requirements regarding input data and the limitations that apply to these methods. If not, success with implementation in the subsequent risk reduction step could be jeopardised and wrong conclusions could be drawn.

\subsubsection{Risk reduction}

The final step in the OSCAR cycle is dedicated to the reduction of seismic risk, i.e. the use of seismicity related information to actively treat, transfer or terminate the sources of hazard and reduce or, where this is not possible, at least minimise exposure to hazards.

Among the main techniques rock engineers and other endusers of seismic information apply in this way are:

- Bracketing seismically active geological features

- Devising methods to safely negotiate structures

- Avoiding layouts and sequences with high seismic energy emission

- Balance between mining rate and seismic response

- Supporting service excavations with high rockburst risk

- Design of stope support systems for dynamic loading

- Real-time processing and reporting of large seismic events ('quick location')

- Classification of working places according to seismic hazard level

- Observation of short and medium term trends in seismicity

- Detection of unusual seismicity patterns
There is a multitude of processes that quantify aspects of mining induced seismicity for the purpose of risk reduction. A common pitfall is to focus on data collection and neglect the utilisation of seismic information to the benefit of the operation and the people working within.

Rock engineers (and production personnel) are in key positions to actively reduce seismic risk by identifying emission sources and eliminating them. Where this is not possible, exposure of people and assets can often be reduced, but it requires familiarity with methods, their objectives and their limitations.

\subsection{Mine Seismology Quantifiers}

A summary of methods and techniques used in mine seismology evidences the way in which the discipline contributes to increased safety in mines: The correlation of seismicity with mine design parameters, geological data, rock mechanics and support design, mine production and loss control information offers numerous ways to quantify and interact with processes that are inherently unsafe or at least carry a appreciable level of risk.

The ability to quantify hazard levels offers the opportunity to use seismic information to optimise operations. Some examples are given here:

- Critical dimensions of stabilising pillars to prevent foundation failure

- Maximum panel leads to prevent abutment failure

- Maximum face length to limit maximum failure size, i.e. maximum magnitude

- Critical remnant size to avoid core failure

- Correlation of medium-term trends in seismic activity with production rate to detect increased hazard levels

- Estimates of recurrence time for large events and maximum event magnitude

- Estimates of peak ground motion in the vicinity of large seismic events

- Classification of working places and geo-technical areas in terms of low and high seismic hazard areas

- Quantification of rockburst risk for working areas and daily shift schedules

- Detection of short-term rockmass instabilities

- Design of safe re-entry procedures after large events

This list is not exhaustive.

Again, in order to ask pertinent questions, rock engineering personnel must be aware of the various methods and the respective types of information mine seismology as a discipline is able to deliver.

\section{TRAINING OUTLINE}

What follows is an outline of training contents to cover mine seismology requirements for rock engineers. The outline accommodates all issues discussed in chapter 2, further expanded by case materials and administrative tasks that rock engineers may have to execute when managing a seismology service contract.

A training course could be split into three main sections, as shown in Table 1, with headings "Seismic Data Collection", "Seismic Data Analysis" and "Seismic Data Interpretation".

\section{SUMMARY}

A structured course with contents summarised as in Table 1 would prepare rock engineers for an active involvement in seismicity related issues. It would also lay the foundation for project work falling into those sectors of rock engineering that deal with dynamic rockmass failure. Mine seismology, like other geotechnical disciplines, depend on integration to produce meaningful results. The more seismic information 
can be placed in the context of geology, rock mechanics, production and mine design, the more beneficial is usually its application.

It would also provide an insurance that suppliers have competent partners on the mine who can take well informed decisions regarding the deployment of resources and can advise the mine in cases where a supplier may find himself in a conflict of interest. Rock engineers who are competent in mine seismology are able to manage external seismology service providers more efficiently and make better use of seismicity related information provided to them.

\section{ACKNOWLEDGMENTS}

The author would like to thank M.J. Dunn, Manager Rock Engineering at AngloGold-Ashanti Ltd for his constructive input into this paper.

\section{REFERENCES}

Gibowicz, S.J. and Kijko, A. (1993) An introduction to mining seismology, Academic Press.

Kijko, A., Lasocki, S. and Graham, G. (1998) SeisHazM: Seismic Hazard in Mines Version 2.1, User Guide, Project report 1999-0161.

Mendecki, A.J. (ed. 1997) Seismic monitoring in mines, Chapman \& Hall.

Oakland, J.S. (2003) Total quality management, Butterworth \& Heineman.

Van der Merwe, M. and Laas, J.J. (1998) SeisDBS - the rock engineering seismic data visualisation tool, SANGORM '98 West Rand Region ISBN 0-9583974-4-9.

TABLE 1 Training contents to achieve rock engineering proficiency in basic mine seismology

\begin{tabular}{|c|c|c|}
\hline \multirow[t]{3}{*}{$\begin{array}{l}\text { Part A } \\
\text { Seismic Data } \\
\text { Collection }\end{array}$} & $\begin{array}{l}\text { 1. Seismic Systems } \\
\text { - Monitoring objectives } \\
\text { - Principal concepts/solutions } \\
\text { - Sensors } \\
\text { - } \text { Data transfer } \\
\text { - Network design } \\
\text { - Limitations }\end{array}$ & $\begin{array}{l}\text { Outcome } \\
\text { Ability to choose monitoring equipment best suited to defined needs; knowledge } \\
\text { of technical and financial requirements of monitoring; knowledge of physical } \\
\text { limitations of technology }\end{array}$ \\
\hline & $\begin{array}{l}\text { 2. Data Processing } \\
\text { - Automatic processing } \\
\text { - } \text { Manual processing } \\
\text { - } \text { Basic parameters } \\
\text { - } \text { Spectral domain } \\
\text { - } \text { First motion } \\
\text { - Moment Tensor }\end{array}$ & $\begin{array}{l}\text { Outcome } \\
\text { Knowledge of hard- and software requirements for seismic data processing; } \\
\text { awareness of issues related to quality of seismic raw data; knowledge of seismic } \\
\text { source quantification methods }\end{array}$ \\
\hline & $\begin{array}{l}\text { 3. Theoretical Seismology } \\
\text { - } \text { Source types } \\
\text { - } \text { Elastic waves } \\
\text { - } \text { Radiation pattern } \\
\text { - Oscillatory motion } \\
\text { - } \text { Wave propagation } \\
\text { - } \text { Interfaces } \\
\text { - } \quad \text { Real and idealised media }\end{array}$ & $\begin{array}{l}\text { Outcome } \\
\text { Knowledge of theoretical concepts of seismic sources, initiation and termination, } \\
\text { strain energy storage and release; knowledge of simplified models of vibration } \\
\text { and their mathematical description; properties of waves and physical principles of } \\
\text { their propagation simplified media }\end{array}$ \\
\hline \multirow[t]{3}{*}{$\begin{array}{l}\text { Part B } \\
\text { Seismic Data } \\
\text { Analysis }\end{array}$} & $\begin{array}{l}\text { 1. Descriptive Statistics } \\
\text { - Classification } \\
\text { - Histograms } \\
\text { - Location } \\
\text { - Variation } \\
\text { - Correlation }\end{array}$ & $\begin{array}{l}\text { Outcome } \\
\text { Knowledge of statistical methods of data analysis and awareness of their limita- } \\
\text { tions }\end{array}$ \\
\hline & $\begin{array}{l}\text { 2. Data manipulation } \\
\text { - Smoothing } \\
\text { - Compression } \\
\text { - Regression } \\
\text { - Probabilities }\end{array}$ & $\begin{array}{l}\text { Outcome } \\
\text { Knowledge of methods of data manipulation and their benefits in terms of trend } \\
\text { and pattern identification }\end{array}$ \\
\hline & $\begin{array}{l}\text { 3. Seismological Tools } \\
\text { - } \quad \text { Time history } \\
\text { - } \text { Gutenberg-Richter relation } \\
\text { - } \text { Maximum size estimates } \\
\text { - } \text { Recurrence time } \\
\text { - } \quad \text { Predictions \& success rate } \\
\text { - Energy-Moment Graph } \\
\text { - Energy/Moment Index } \\
\text { - } \quad \text { Ground-Motion Relation } \\
\text { - } \quad \text { Seismic hazard assessment }\end{array}$ & $\begin{array}{l}\text { Outcome } \\
\text { Ability to choose from a wide selection of tools to create desired types of } \\
\text { information; ability to direct service provider w.r.t. deliverables; ability to formulate } \\
\text { relevant questions and seek comprehensive answers; familiarity with limitations of } \\
\text { methods and common pitfalls }\end{array}$ \\
\hline
\end{tabular}




\begin{tabular}{|c|c|c|}
\hline \multirow[t]{4}{*}{$\begin{array}{l}\text { Part C } \\
\text { Seismic Data } \\
\text { Interpretation }\end{array}$} & $\begin{array}{l}\text { 1. Application I: Single event } \\
\text { - Source location } \\
\text { - Source parameters } \\
\text { - } \text { Failure mechanism } \\
\text { - } \text { Zamage mechanism } \\
\text { - } \text { of influence }\end{array}$ & $\begin{array}{l}\text { Outcome } \\
\text { Interpretation of basic source parameters as quantified by seismic monitoring } \\
\text { equipment; physical interpretation of parameters and their significance for } \\
\text { source interpretation; correlation between underground observations and source } \\
\text { parameters (location, source dimension, source mechanism) }\end{array}$ \\
\hline & $\begin{array}{l}\text { 2. Application II: Event clusters } \\
\text { - Trends over time } \\
\text { - Patterns in space } \\
\text { - Seismically active } \\
\text { - Rockburst prone } \\
\text { - Instability concept } \\
\text { - } \text { Mine design parameters }\end{array}$ & $\begin{array}{l}\text { Outcome } \\
\text { Ability to identify trends and trend changes in seismic data; ability to recognise } \\
\text { patterns; correlation of observed changes with mining and geotechnical param- } \\
\text { eters; classification of working places and geotechnical areas into various seismic } \\
\text { risk categories }\end{array}$ \\
\hline & $\begin{array}{l}\text { 3. Application III: Losses } \\
\text { - Rockburst reports } \\
\text { - Damage classification } \\
\text { - Ground motion vs. damage } \\
\text { - Threshold of relevance } \\
\text { - Local rockburst scenario } \\
\text { - } \text { (In)direct costs } \\
\text { - Contingency planning }\end{array}$ & $\begin{array}{l}\text { Outcome } \\
\text { Ability to document rockbursts and associated damage; ability to estimate ground } \\
\text { motion characteristics for support design and hazard classification; ability to } \\
\text { quantify rockburst related losses and their financial implication; ability to utilise } \\
\text { knowledge gained from rockburst report analysis to reduce seismic hazard and } \\
\text { mitigate its consequences }\end{array}$ \\
\hline & $\begin{array}{l}\text { 4. Administration } \\
\text { - } \quad \text { Contract law } \\
\text { - } \text { Quality management } \\
\text { - } \text { Auditing } \\
\text { - } \text { Mine Health \& Safety Act } \\
\text { Other legal requirements }\end{array}$ & $\begin{array}{l}\text { Outcome } \\
\text { Knowledge of contract law; ability to evaluate data quality and aspects of seismic } \\
\text { system performance; awareness of legal requirements in the field of health and } \\
\text { safety }\end{array}$ \\
\hline
\end{tabular}

